\title{
David Oliver: Challenges for rural hospitals-the same but different
}

\section{David Oliver consultant in geriatrics and acute general medicine}

Berkshire

The UK is densely populated. Even Scotland, with only 62 people per square kilometre, pales in sparseness next to Canada or Australia, whose densities are 3.2 and 2.6, respectively. ${ }^{1}$

Even so, our rural areas face distinct challenges, and the problems facing urban health systems are exacerbated in the countryside: less car ownership, worse public transport, longer travel times to GP surgeries. Practices are smaller and have more difficulty attracting GPs. The hospital is often a long round trip from patients' homes. Distance makes access to moderate level urgent and ambulatory care crucial, as is rehabilitation or end of life care at or close to home, as well as family and social networks. $^{23}$

Community hospitals, where they exist, can be used as a hub. GPs, paramedics, allied professionals, and nurse practitioners with enhanced skills and roles are invaluable. ${ }^{4}$

Rural areas aren't homogeneous. Alongside bucolic idylls, much rural deprivation exists: social isolation, single occupier households, and unfit housing stock are more prevalent. Rural and coastal communities have a high proportion of older residents, compounded by "urban drift" in younger people.

Much rural deprivation exists: social isolation, single occupier households, and unfit housing stock are more prevalent

It's harder to attract a workforce to low paid caring jobs. Community practitioners and teams take longer travelling to and between patients' homes. Funding formulas don't reflect these additional costs, further disadvantaging rural areas.

And reconfiguration of health services based on urban models risks leaving whole regions without a hospital. Some specialised services clearly benefit from centralisation, but a smaller rural hospital should be able to do a great deal, including level 2 urgent care. In sparsely populated countries such as Australia, hospitals much smaller than the UK's can provide a wide range of services.

The lower patient volume and smaller peer group can make posts less attractive to subspecialists who want to maintain specialty interest and skills. Parallel rotas for acute, internal, and geriatric medicine, for example, may be unviable. ${ }^{6}$

There's a pressing need for confident expert generalists happy to deal with most of what comes their way and for peripatetic hospital clinicians providing clinical support beyond the hospital's walls. It's especially hard to attract consultants to these roles, so substantive posts and rotas go unfilled. Doctors tend to settle in the region where they complete specialist training, often with a family base in the town. ${ }^{7}$ Medical school places are disproportionately concentrated in big cities, limiting trainees' exposure to rural medicine. ${ }^{89}$ Doctor-patient ratios and applications for training posts are higher in the metropolis.

If we want to ensure fair access to care in rural populations, tailored to their unique circumstances, we need plans to tackle these issues. And we have to start by recognising that their needs are the same but different.

Competing interests: See www.bmj.com/about-bmj/freelancecontributors/david-oliver.

Provenance and peer review: Commissioned; not externally peer reviewed.

1 List of countries by population density. Statistics Times 16 Apr 2015. http://statisticstimes. com/population/countries-by-population-density.php.

2 Scottish Government. Remote and rural healthcare. Dec 2015. www.gov.scot/Topics/ Health/Services/Rural-Healthcare.

Nuffield Trust. Shaping the future of rural and remote health care. 2016. https://www. nuffieldtrust.org.uk/event/shaping-the-future-of-rural-and-remote-health-care.

4 Royal College of General Practitioners. Being rural: exploring sustainable solutions for remote and rural healthcare (RCGP Scotland Policy Paper written by the Rural Strategy Group Scotland). Aug 2014. www.rcgp.org.uk/-/media/Files/Policy/A-Z-policy/RCGPBeing-Rural-policy-paper-and-appendix-2014.ashx?la=en.

5 Edwards N. Making rural hospitals sustainable. Nuffield Trust. 12 Jul 2016. https://www. nuffieldtrust.org.uk/news-item/making-rural-hospitals-sustainable\#so-what-are-some-ofthe-solutions.

$6 \quad$ Nuffield Trust. Acute care in remote settings: challenges and potential solutions. $12 \mathrm{Ju}$ 2016. https://www.nuffieldtrust.org.uk/research/acute-care-in-remote-settings-challengesand-potential-solutions.

7 Royal College of Physicians. 2014-15 census (UK consultants and higher specialty trainees). 1 Feb 2016. https://www.rcplondon.ac.uk/projects/outputs/2014-15-census-ukconsultants-and-higher-specialty-trainees.

8 Royal College of Physicians. Physicians on the front line: the medical workforce in Wales in 2016. 17 Nov 2016. https://www.rcplondon.ac.uk/projects/outputs/physicians-front-linemedical-workforce-wales-2016-0. 
9 Medianet. Redistribution of medical school places not the sole solution for rural medical workforce. 9 Mar 2017. www.medianet.com. au/releases/release-details/?id=875286.
Published by the BMJ Publishing Group Limited. For permission to use (where not already granted under a licence) please go to http://group.bmj.com/group/rights-licensing/ permissions 